\title{
A Letter to President Biden and Secretary Designate of HHS Xavier Becerra: Remove Barriers to Federal Funding of Human Embryo and Fetal Tissue Research
}

\author{
Nanette Santoro $^{1}$ (D) Arthur Caplan ${ }^{2} \cdot$ Jerome Strauss $^{3} \cdot$ Virginia D. Winn ${ }^{4}$ \\ Received: 13 January 2021 / Accepted: 8 February 2021 / Published online: 26 February 2021 \\ (C) Society for Reproductive Investigation 2021
}

\begin{abstract}
Human fetal tissue (HFT) has been used in biomedical research for nearly a century and has led to extraordinarily valuable discoveries that have benefitted humankind. Politicization of the use of HFT over recent years has led to the creation of numerous obstacles to scientific progress in this field. In July 2019, the imposition of redundant ethics policies was supplemented with the creation of the Human Fetal Tissue Ethics Advisory Board, which withheld funding of 13 out of 14 NIH grants that were favorably peer reviewed in the Summer of 2020. We believe that these new sets of restrictions are harmful to the goals of scientific progress and call upon the new administration of our government to allow peer review, not politics, to determine scientific merit and to reinstitute the previously existing ethics policies that were more than adequate to assure the appropriateness of human fetal tissue research.
\end{abstract}

Keywords Human fetal tissue $\cdot$ biomedical research $\cdot$ vaccines

Research on human embryos and fetal tissue has contributed to major medical advances. Here is a list, which is by no means all inclusive:

- The development of the polio, rabies, hepatitis A, varicella, and rubella vaccines relied on fetal fibroblast cells for their creation [1].

- The study of how viruses infect cells, especially HIV. There are no suitable animal models for HIV infection, and the standard infectious disease model for humans, the macaque, gets infected with SIV instead of HIV.

- Creation of mice with "humanized" immune systems derived from human fetal tissue has been invaluable for the

Nanette Santoro

Nanette.Santoro@cuanschutz.edu

1 Department of Obstetrics and Gynecology, University of Colorado School of Medicine, Aurora, CO, USA

2 NYU Grossman School of Medicine, New York, NY, USA

3 Virginia Commonwealth University School of Medicine, Richmond, VA, USA

4 Stanford University School of Medicine, Palo Alto, CA, USA study of HIV and other viral pathology and for vaccine testing.

- Immune therapies for cancer, again through the use of mice with humanized immune systems

- The study of how inherited diseases affect human development

- Fetal tissue transplantation to treat Parkinson's disease, amyotrophic lateral sclerosis, spinal cord injury, and diabetes

- The study of how viruses such as Zika and other infections affect the fetus

- The study of complications caused by dysfunction of the placenta that leads to maternal and neonatal morbidity and mortality

- The study of early steps in the establishment of human pregnancy including causes of infertility, pregnancy loss, and pregnancy complications like preeclampsia

- The development of human embryonic stem cells

- The development of intracytoplasmic sperm injection, a major treatment for male infertility

- The development of pre-implantation embryo biopsy and genetic screening and diagnosis

Sadly, actions taken by the Trump Administration effectively blocked the use of human fetal tissue for federally funded biomedical research. In 2019, a new policy by this 
administration prohibited the use of fetal tissue from abortion procedures in any intramural NIH research. The University of California at San Francisco was not renewed for further funding of a multi-year contract using human fetal tissue in mice to research HIV therapies [2].

The July 26, 2019, regulations for human fetal tissue research (NOT-OD-19-128) for the first time include restrictions on funding research on human extra-embryonic cells and tissue, such as the umbilical cord, cord blood, placenta, fetal membranes, and amniotic fluid [3]. This restriction continues to hamper advancements initiated by the NIH Human Placenta Project. Furthermore, under these new regulations (NOT-OD-19-128), research grants that received fundable scores through the peer review process were subjected to an additional level of review by a newly appointed Human Fetal Tissue Research Ethics Advisory Board. Of 14 proposals brought to the Board in July 2020, only 1 did not have funding withheld (by an 8 to 7 vote). The objective of this proposal was to develop an alternative to human fetal tissue. The recommendation for the remaining 13 proposals was to withhold funding. Although the Board was supposed to use only "ethical considerations" in deciding whether or not to fund a proposal, reasons to withhold funding included the following: insufficient justification for the use of the tissue; failure to rationalize the amount of tissue sought; perceived inadequacies in informed consent forms (despite the fact institutional ethics committees had already approved all of these proposals before they came before the Board); and disapproval of the use of human fetal tissue for the sole purpose of comparing it to an alternative to fetal tissue $[4,5]$.

It is important to recognize that the use of human fetal tissue in research is already strictly regulated. Since 1993, all grants using human fetal tissue (at the time extraembryonic tissue was not included) require a statement of compliance with sections 498A and 498B of the Public Health Serve Act and the NIH Grants Policy Statement [6]. Regulations prohibit payment for human fetal tissue other than for costs associated with acquisition or storage. Informed consent is required from any pregnant person undergoing an abortion in order to accept human fetal tissue for research. The law clearly indicates that any change in the clinical management of abortion, for example, changes in the timing or method of the abortion to facilitate the research, must not occur. The addition of the Human Fetal Tissue Research Ethics Advisory Board adds a barrier that goes well beyond the existing Federal and ethical guidelines that have been established for this research. Nor is the board open-minded. At least 10 of the 15 members of the Advisory Board have publicly opposed abortion, fetal tissue research, stem cell research, or, amazingly, contraception.

Fetal tissue is defined under the new policy as "human fetal tissue (HFT) or extraembryonic (placental) tissue from elective abortions" and refers to any tissue or organ obtained from a fetus or placenta that was fertilized at least 8 weeks earlier.
Investigators requesting the use of fetal/placental tissue must comply with a new set of requirements, which are redundant with what is already embedded in existing law. The following items must be explicitly addressed within the Approach section of the Research Strategy portion of the application:

- Indicate why the research goals cannot be accomplished using an alternative to HFT (including, but not limited to, induced pluripotent cells not developed from HFT, organoids not developed from HFT, neonatal human tissue, human tissue obtained from adults, human fetal tissue not derived from elective abortion, animal models, and in vitro models that are not developed from HFT, and computational models)

- Indicate the methods used to determine that no alternatives to HFT can be used (including, but not limited to, literature review and preliminary experiments)

- Conduct and describe results from a literature review used to provide justifications

- Describe plans for treatment of HFT and the disposal of HFT when research is complete

- Describe planned written, voluntary, informed consent process for cell/tissue donation, or description and documentation of process if cells/tissue were already obtained. Include a sample of the IRB-approved informed consent form with the application or during the Just-in-Time (JIT) process. The informed consent for donation of HFT for use in research requires language that acknowledges informed consent for donation of HFT was obtained by someone other than the person who obtained the informed consent for abortion, occurred after the informed consent for abortion, and will not affect the method of abortion; no enticements, benefits, or financial incentives were used at any level of the process to incentivize abortion or the donation of HFT; and to be signed by both the woman and the person who obtains the informed consent [3].

The required information is of the type usually presented in the Human Subjects section of a grant proposal. Yet, the new regulations require that it be incorporated into a 12-page Research Strategy limit. This is another example of an artificial barrier to the investigator, who must now compress the presentation of the all-important scientific premise, objectives, and methods to accommodate material that could be described elsewhere in the application.

As members of the scientific community, we must speak up and speak out when unjust and ill-advised policies interfere with the progress of biomedical research that benefits the American people and public health. Crude, politically motivated barriers to research by opponents of abortion, contraception, stem cell research, and human fetal tissue research should not be allowed to interfere with scientific inquiry [7]. The National Academy of Medicine last visited this issue in 
1994 and acknowledged the importance of fetal tissue research in producing "one of the major medical breakthroughs of our time [polio vaccine development] [8]." Women undergoing abortion who are carrying a fetus with a diagnosis incompatible with life feel comfort in contributing to research that may prevent or reduce the impact of disease [9]. For others, the donation of fetal tissue for the common good may help with the coping and recovery process after the often agonizing decision to end their pregnancy [10].

We must resist and oppose attempts to "normalize" the behavior of the Human Fetal Tissue Research Ethics Advisory Board. It is not an "ethical" body and it is inappropriately named. It is an ideologically driven obstructive force that seeks to prevent scientific progress that most Americans already routinely take advantage of through immunizations and cancer and transplant therapies. At least in the case of human embryonic stem cell research, they support this research by a $2 / 3$ margin. The recent restrictive activities of the HHS have been publicly opposed by many including the prestigious International Society for Stem Cell Research:

With these new arbitrary restrictions on research, the United States is ceding its role as the global leader in the development of cellular therapies and regenerative medicine. Americans will now wait for life-saving therapies to be developed in Europe, Asia, and other parts of the world [11].

We ought not permit the suppression of scientific inquiry that the Trump administration allowed to take place. The lives of our politicians, our citizen, our families, and of future generations depend on overturning a poorly constructed policy that hinders finding new tests, cures, and fundamental knowledge.

\section{Declarations}

This manuscript is an editorial piece that did not involve the recruitment of human subjects or animal experimentation. It represents the opinion of the authors. There is no IRB or ethics approval requirement for this piece. In fact, one of the authors is a widely published ethicist.

Conflict of Interest The authors declare no competing interests.

Disclaimer The authors of this piece are writing as individuals, and not on behalf of their Universities.

\section{References}

1. https://www.chop.edu/centers-programs/vaccine-education-center/ vaccine-ingredients/fetal-tissues

2. https://www.spectrumnews.org/news/trumps-fetal-tissue-policyimpacts-medical-research/

3. https://grants.nih.gov/grants/guide/notice-files/NOT-OD-19-128. html

4. https://abcnews.go.com/Health/wireStory/trump-ending-fetaltissue-research-federal-scientists-63506968

5. https://www.sciencemag.org/news/2020/08/new-us-ethics-boardrejects-most-human-fetal-tissue-research-proposals

6. https://www.ama-assn.org/delivering-care/ethics/research-usinghuman-fetal-tissue

7. https://www.aaas.org/survey-most-americans-support-stem-cellresearch

8. Institute of Medicine. 1994. Fetal Research and Applications: A Conference Summary. Washington, DC: The National Academies Press. https://doi.org/10.17226/4797.

9. Anderson F, Glasier A, Ross J, Baird DT. Attitudes of women to fetal tissue research. J Med Ethics. 1994;20:36-40.

10. Evans MDR, Kelley J. US attitudes toward human embryonic stem cell research. Nature Biotech. 2011;29:484-8.

11. https://www.isscr.org/news-publicationsss/isscr-news-articles/ article-listing/2019/06/05/isscr-opposes-health-and-humanservices-policy-restricting-fetal-tissue-research

Publisher's Note Springer Nature remains neutral with regard to jurisdictional claims in published maps and institutional affiliations. 